\title{
Predictive Factors in the Onset of Epilepsy in Children with Cerebral Palsy
}

\author{
Todoran Butilă Anamaria*, Sin Anca, Micheu Cristian, Csep Katalin, Voidăzan Septimiu, Racos Szabo \\ Elisabeta
}

University of Medicine and Pharmacy of Tirgu Mures, Romania

\begin{abstract}
Objectives: the aim of the study was to identify predictive risk factors of the development of epilepsy in patients with cerebral palsy (CP). Materials and methods: We performed a bidirectional study in wich 177 patients diagnosed with CP with and without epilepsy have been selected for characteristics and risk factor comparison. We analyzed the history related to pregnancy and birth, gestational age, birth weight, fetal distress, the presence of neonatal convulsion, age of onset for the epilepsy, associated types of seizures, the response to anticonvulsant therapy and brain changes identified by Computer tomography and Magnetic resonance imaging examination.

Results: epilepsy was found in 91 (51.4\%) patients, most frequently in quadriplegic form (76.2\% vs 23.8\%), OR:3.04, 95\% Cl:1.42-6.52, p-0.005. In this group, the most common were partial seizures (34.4\%), epileptic encephalopathy like Lennox Gastaut and West type (62.5\%), and also neonatal seizures. Eighty percent of on-term infants with neonatal seizures later developed epilepsy. Factors like fetal distress, low birth weight, cytomegalovirus infection, history of pathological pregnancy were associated with an increased risk of developing epilepsy. Imaging change, especially cerebral atrophy had the highest frequency (37.5\% vs 16\%) in pacients with epilepsy. 28 (30.8\%) patients had resistance epilepsy, 13 (46.4\%) of them having quadriplegia. Early onset of epilepsy constitutes a sign of severity of epileptic forms (OR:3.09, 95\% Cl:1.187-8.061, p-0.01).

Conclusions: The data are consistent with those in literature but is necessary following this study to clarify and support the assumption on preddictive factors and prognosis of epilepsy in this population.
\end{abstract}

Keywords: predictive factors, epilepsy, cerebral palsy, children

Received: 09 December 2014 / Accepted: 04 June 2015

\section{Introduction}

Epilepsy is the most dynamic area of neuroscience in general and of children in particular, being a very common pathology associated with cerebral palsy, this being demonstrated in numerous studies in the field. $[1,5,8,10,15,17]$

Cerebral palsies (CP) are static encephalopathies with an early onset and non-progressive (but not necessarily unaltered) caused by a damage on the immature or developing brain before the age of 3-4 years, that is characterized by persistent disorders in movement, posture, tone and motor functions. [1-4] The incidence of seizures in patients with cerebral palsy varies between $15-90 \%$, depending on the study groups, the types of seizures considered and the form of cerebral palsy. [5-9] Several studies in recent years which have included children with cerebral palsy and epilepsy highlighted a number of features of epilepsies associated with forms of CP. [6,7,10-12]. However few studies have attempted to identify and associate risk predictors in the development of epilepsy with this pathology $[5,8,13]$.

Parameters such as: pregnancy and birth history, gestational age, birth weight, fetal distress, the presence of neonatal convulsion, opportunistic infections like TORCH syndrome, age of onset for epilepsy, types of seizures associated with the response to anticonvulsant therapy, abnormal cerebral lesions identified by CT and MRI investigations

* Correspondence to: Anamaria Todoran Butilă

E-mail: anetodoranb@gmail.com were examined in this study in order to highlight a correlation between predictive factors, risk of epileptogenesis, type of seizures and response to antiepileptic treatment in children with cerebral palsy.

\section{Material and Methods}

The study included 177 patients with age between 2-17 years, patients hospitalized in the Clinic of Pediatric Neurology and Psychiatry Tîrgu Mureş, all diagnosed with cerebral palsy and followed between 2011-2014. Patients have been included in two groups according to the presence or absence of epilepsy. Group 1 with 86 cases - 50 (58.1\%) boys and 36 (41.9\%) girls - comprised patients with only cerebral palsy having a median age of 5.7 years (2-17.7 years). Group 2 consisted of 91 cases of cerebral palsy with epilepsy - 49 (53.8\%) boys and $42(46.2 \%)$ girls - with a median age of 5.6 years (2 to 17.8 years). From the study were excluded patients with neuromuscular, neurometabolic or genetic and neurodegenerative diseases, all these pathologies presenting clinical motor deficiencies. The type of cerebral palsy was determined based on the neurological examination performed for each patient: spastic form (quadriplegia, diplegia, triplegia hemiplegia), ataxic, dyskinetic, mixed form (hypotonic-ataxic) and the unclassifiable forms (intermediate forms)[4]. The patients from group 2 required the confirmation of the epilepsy diagnosis, namely the presence of at least two seizures, unprovoked (excluding febrile seizures or single crisis 
and convulsions in the neonatal period), accompanied by epileptiform type changes in the electroencephalographic pathway. Classification of epilepsies and seizures was done in accordance with the recommendations of the International League Against Epilepsy organization [14]: primary generalized tonic-clonic seizures, partial seizures with or without secondary generalization, infantile spasms, myoclonic seizures, typical or atypical absence, tonic, clonic seizures. There were situations in which the type of seizures could not be identified, these were deemed unclassifiable. The majority of seizures were symptomatic, and there were some cases of child specific syndromes, namely epileptic encephalopathies (of which West and LennoxGastaut syndrome were predominant). The patients presented different types of seizures over time, in such cases the type of onset seizures was considered in the statistical calculation. Parameters examined regarding epileptogenic risk factors were: the history of pregnancy, type of birth (cesarian-section, natural, the presence or absence of hypoxia), gestational age (early preterm $<32$ weeks, preterm 32-36 weeks, on term > 37 weeks ) [15]; birth weight $(<1500 \mathrm{~g}, 1500-2500 \mathrm{~g},>2500 \mathrm{~g})$, APGAR score (high: $\geq 7 / 1 \mathrm{~min}, \geq 8 / 5 \mathrm{~min}$, moderate: $3-5 / 1 \mathrm{~min}, 4-7 / 5 \mathrm{~min}$, low: $\leq 3 / 1 \mathrm{~min}, \leq 3 / 5 \mathrm{~min}$ ) [8] and also newborn resuscitation techniques were considered. A comparative analysis was performed regarding the presence/absence of neonatal seizures, TORCH infections and abnormal cerebral changes detectable by imaging investigations (computer tomography - CT and cerebral magnetic resonance - MRI). The evolution of patients was followed for at least one year, the period necessary to establish the form of epilepsy responsive or resistant to antiepileptic therapy. The cases which were considered responsive to treatment where the ones when, for one or more antiepileptic drugs in maximum tolerated doses, a control of the seizures for at least one year was obtained, the presence of more than four seizures in one year being considered treatment resistant [16].

Written informed consent was obtained from all parent of this children. The study was approved by the Ethics
Committee of the University of Medicine and Pharmacy Tîrgu Mureş.

The statistical analysis was performed using the MedCalc Software, Version 12.5.0.0. Data was considered nominal or quantitative variables. Nominal variables were characterized using frequencies. Quantitative variables were tested for normality of distribution using the Kolmogorov-Smirnov test and were characterized by median and percentiles (25-75\%) or by median and standard deviation (SD), when appropriate. A chi-square test was used in order to compare the frequencies of nominal variables. Quantitative variables were compared using t or Mann-Whitney test when appropriate. Multivariate analysis was carried out using logistic regressions. Odds ratio $(\mathrm{OR})$ and $95 \%$ confidence interval $(\mathrm{CI})$ were calculated after adjustment by confounder variables using the logistic regression method. The level of statistical significance was set at $\mathrm{p}<0.05$.

\section{Result}

In regards of gender distribution in the two groups ( $\mathrm{p}$ $0.67)$, origin ( $\mathrm{p}-0.43)$, family, history of epilepsy ( $\mathrm{p}-0.40)$, no statistically significant differences were recorded.

\section{Cerebral palsy, neonatal seizures, onset epilepsy, sei- zures correlation with forms of cerebral palsy}

Of the 177 patients selected, 91 (51.4\%) developed epilepsy, 49 (53.8\%) of these presenting seizures in the first year of their life, only 13 cases $(14.3 \%)$ recorded late onset of seizures, after the age of 5 years. The median age of seizure onset was $11.5(0-156)$ months. Quadriplegia and hemiplegia were disabilities most commonly associated with epilepsies, mixed forms being also a predictive factor. The types of cerebral palsy identified among patients with and without epilepsy and seizure types associated with each subgroup of cerebral palsy are shown in Table I. It is noted that epilepsy is a condition commonly associated with forms of quadriplegia (76.2\% epileptic CP vs $23.8 \%$ only CP) with OR:3.04, 95\% CI:1.42-6.52, with a highly sta-

Table I. Distribution of forms of cerebral palsy in the two groups and associated types of seizures in the epileptic patients group

\begin{tabular}{|c|c|c|c|c|}
\hline CP subgroup & $\begin{array}{l}\text { CP without epi- } \\
\text { lepsy } n(\%)\end{array}$ & $\begin{array}{l}\text { CP with epilepsy } \\
\mathrm{n}(\%)\end{array}$ & $\begin{array}{l}\text { Total } \\
\mathrm{n}(\%)\end{array}$ & $p$ value ${ }^{*}$ \\
\hline Quadriplegia & $10(11.6)$ & $\begin{array}{l}32 \text { (35.2) (4 GTCS, } 3 \text { infantile spasms , } 4 \text { W, } 6 \text { LG, } \\
11 \text { partial sz, } 4 \text { myoclonic sz, } 1 \text { tonic sz, } 1 \text { clonic sz) }\end{array}$ & $42(23.7)$ & 0.005 \\
\hline Triplegia & $2(2.32)$ & - & $2(1.1)$ & 0.45 \\
\hline Hemiplegia & $11(12.8)$ & $\begin{array}{c}21 \text { (23.0) (3 GTCS, } 1 \text { infantile spasms,1 not classified, } \\
\text { 1clonic sz, } 15 \text { partial sz) }\end{array}$ & $34(19.2)$ & 0.11 \\
\hline Ataxic & $20(23,2)$ & $\begin{array}{c}8 \text { (8.8) (2 GTCS, } 1 \text { infantile spasms, } 3 \text { tonic sz, } \\
1 \text { myoclonic absences, } 1 \text { myoclonic sz) }\end{array}$ & $28(15.8)$ & 0.01 \\
\hline Dyskinetic & $5(5.8)$ & 5 (5.4) (1 GTCS, 1 infantile spasms, 3 myoclonic sz) & $10(5.6)$ & 0.92 \\
\hline $\begin{array}{l}\text { Mixed } \\
\text { (hypoton- ataxic ) }\end{array}$ & $15(17.4)$ & $\begin{array}{l}9(9,9) \text { (2West sy, 2LG sy, } 3 \text { partial sz, } \\
1 \text { myoclonic absences, 1myoclonic sz) }\end{array}$ & $24(13.5)$ & 0.21 \\
\hline $\begin{array}{l}\text { Not classifiable } \\
\text { (intermediate type) }\end{array}$ & $9(10.4)$ & $\begin{array}{l}11 \text { (12.1) (2 GTCS, } 1 \text { infantile spasms, } 1 \text { West sy, } 1 \text { LG sy, } \\
1 \text { tonic sz, } 3 \text { partial sz, } 1 \text { amyotonic sz, } 1 \text { myoclonic sz) }\end{array}$ & $20(11.2)$ & 0.90 \\
\hline Total & $86(100 \%)$ & $\begin{array}{c}91 \text { (100\%) (12 GTCS, } 7 \text { infantile spasms, } 37 \text { partial sz, } 10 \text { myoclonic sz, } \\
2 \text { clonic sz, } 5 \text { tonic sz, } 2 \text { absences sz, myoclonic sz, } 1 \text { amyotonic sz, } \\
1 \text { not classified ,7West sy, 9LG sy ) }\end{array}$ & $177(100 \%)$ & \\
\hline
\end{tabular}


tistically significant $\mathrm{p}-0.005$. In this group, the most common were partial seizures with or without secondary generalization (34.4\%), primary generalized GTCS (12.5\%) and infantile spasms (9.4\%), epileptic encephalopathy like West syndrome and Lennox Gastaut type representing $62.5 \%$ of those 16 cases diagnosed with this form of epilepsy. Summarizing the types of epileptic seizures in the entire group (91 patients), partial seizures, GTCS, myoclonic seizures and spasms were shown in most cases.

The role of neonatal seizures in the development of epilepsy

Within the combined groups, $21(11.9 \%)$ patients had neonatal seizures. Of these, $16(76.2 \%)$ subsequently developed epilepsy (OR:3.45, CI:1.206-9.900, p-0.01) and $12(75 \%)$ had a clinical picture of quadriplegia (OR:12.8, $\mathrm{Cl} 1.68-238.3, \mathrm{p}-0.04)$. Regarding the gestational age of the patients, the following was observed: 114 (64.4\%) were on-term infants, of whom 15 (13.2\%) had neonatal seizures, and $12(80 \%)$ subsequently developing epilepsy. The other $59(33.3 \%)$ were preterm, $6(10.2 \%)$ of them with a history of neonatal seizures, $4(66.6 \%)$ evolving with epilepsy.

Another evaluated parameter was the frequency and type of convulsive seizures in patients with a history of neonatal seizures. This way it was shown that GTCS and infantile spasms, in equal proportions (by $31.25 \%$ ), were most frequent, followed by myoclonus (25\%); partial seizures were present in a small proportion (12.5\%).

Pre-, peri- and postnatal risk factors associated with the development of epilepsy

A number of factors presumed to be potentially epileptogenic, such as gestational age, low birth weight, presence of postnatal resuscitation manoeuvres, prolonged jaundice were not identified as risk factors in the development of epilepsy, being distributed in similar proportions in both groups. No association was found with birth by caesarean section after the analysis of the two groups ( $\mathrm{p}-0.72)$. Prolonged labor was more frequent in the group of epileptic versus non-epileptic $(61.1 \%$ vs $38.9 \%)$ but with no evident statistical significance (p-0.52). Studies of neonatal parameters taken into account in the two groups are outlined in Table II.

Low Apgar score ( $\leq 3 / 1 \mathrm{~min}, \leq 3 / 5 \mathrm{~min})$ was more frequently seen in patients with epilepsy (19.8\% vs $5.8 \%)$ compared to non-epileptics (p-0.01). The statistical data also showed significant increase in the frequency of $\mathrm{Cy}$ tomegalovirus infection, thus TORCH syndrome representing a risk factor associated with epilepsy (OR:2.24, $\mathrm{p}-0.04)$. For the above risk factors we applied a multivariate logistic regression, considering the dependent variable cerebral palsy and independent variables: neonatal seizures, gestational age, and birth weight, Apgar score at 1-5 minutes, multiple pregnancies and pathological pregnancies. In children with cerebral palsy, epilepsy may develop in the presence of neonatal seizures, multiple and pathological pregnancies, and low Apgar score at 1 minute. Birth weight, gestational age and Apgar score at 5 minutes, however, were not identified as risk factors of epilepsy in cerebral palsy patients (in these situations). The magnitude of risk (OR) associated with these factors for developing epilepsy is represented in Table III.

\section{Analysis based on cerebral lesions identified by brain imaging investigations}

Brain imaging was available for 138 (78\%) patients from the both groups, 39 (22.0\%) not being submitted to brain

Table II. Neonatal parameters

\begin{tabular}{|c|c|c|c|}
\hline Neonatal period characteristics & $\begin{array}{l}\text { Patients with CP and epilepsy } \\
\qquad(91) \\
\mathrm{n}(\%)\end{array}$ & $\begin{array}{c}\text { Patients with CP without epilepsy } \\
\qquad(86) \\
\mathrm{n}(\%)\end{array}$ & $P$ value \\
\hline Prematurity & $26(28.6)$ & $33(38.4)$ & 0.22 \\
\hline Neonatal seizures & $16(17.6)$ & $5(5.8)$ & 0.02 \\
\hline Birth hypoxia & $58(63.7)$ & $44(51.2)$ & 0.12 \\
\hline Resuscitation manoeuvres & $31(34.0)$ & $32(37.2)$ & 0.77 \\
\hline Prolonged jaundice & $6(6.6)$ & $7(8.2)$ & 0.56 \\
\hline $\begin{array}{l}\text { Gestational age : } \\
<32 \text { weeks } \\
\text { 32-36 weeks } \\
>37 \text { weeks }\end{array}$ & $\begin{array}{l}11(12.1) \\
15(16.5) \\
65(71.4)\end{array}$ & $\begin{array}{c}20(23.3) \\
9(10.5) \\
57(66.3)\end{array}$ & $\begin{array}{l}0.05 \\
0.34 \\
0.56\end{array}$ \\
\hline $\begin{array}{l}\text { Birth weight: } \\
<1500 \mathrm{~g} \text {, } \\
1500-2500 \mathrm{~g} \\
>2500 \mathrm{~g}\end{array}$ & $\begin{array}{c}8(8.8) \\
17(18.7) \\
66(72.5)\end{array}$ & $\begin{array}{c}9(10.5) \\
25(29.1) \\
52(60.5)\end{array}$ & $\begin{array}{l}0.89 \\
0.14 \\
0.12\end{array}$ \\
\hline $\begin{array}{l}\text { APGAR score: } \\
\text { high :7/1min, } \geq 8 / 5 \mathrm{~min} \\
\text { moderate:3-5/1min, } 4-7 / 5 \mathrm{~min} \\
\text { low: } \leq 3 / 1 \mathrm{~min}, \leq 3 / 5 \mathrm{~min}\end{array}$ & $\begin{aligned} 64 & (70.3) \\
9 & (9.9) \\
18 & (19.8)\end{aligned}$ & $\begin{array}{c}70(81.4) \\
11(12.8) \\
5(5.8)\end{array}$ & $\begin{array}{l}0.12 \\
0.71 \\
0.01\end{array}$ \\
\hline $\begin{array}{l}\text { TORCH infections } \\
\text { CMV } \\
\text { HSV } \\
\text { TOXO }\end{array}$ & $\begin{array}{c}30(32.9) \\
13(14.3) \\
7(7.7)\end{array}$ & $\begin{array}{c}16(18.6) \\
7(8.2) \\
1(1.2)\end{array}$ & $\begin{array}{l}0.04 \\
0.29 \\
0.08\end{array}$ \\
\hline
\end{tabular}


Table III. Analysis of risk factors through multivariate logistic regression

\begin{tabular}{lccc}
\hline Variable & Odds Ratio & $95 \% \mathrm{Cl}$ & $\mathrm{P}$ value* \\
\hline Neonatal seizures & 2.28 & 1.7186 to 7.2394 & 0.05 \\
Gestational age & 1.04 & 0.9256 to 1.1842 & 0.46 \\
Birth weight & 1.00 & 0.9998 to 1.0011 & 0.19 \\
Apgar score at 1minute & 1.70 & 1.0938 to 1.9155 & 0.05 \\
Apgar score at 5 minute & 1.19 & 0.7819 to 1.8302 & 0.40 \\
Multiple birth & 1.93 & 1.2546 to 3.9061 & 0.05 \\
Pathological pregnancy & 1.77 & 1.8998 to 3.4843 & 0.05 \\
\hline * chi test square & & &
\end{tabular}

imaging investigations; their distribution is summarized in Table IV. 88 (96.7\%) of the epileptic patients could be analysed using CT and MRI images, and for those with cerebral palsy only $50(58.1 \%)$ were analyzed using CT and MRI imaging. CT examinations were performed for $100(72.46 \%)$ patients, $25(18.1 \%)$ received MRI and $13(9.4 \%)$ underwent both types of investigation. In the group of epilepsy patients statistically significant imaging changes were more common than in the group of nonepileptic patients with (p-0.01), of these, atrophies represented $37.5 \%$ with a statistically significant $\mathrm{p}-0.01$. After multivariate analysis, where the presence versus the absence of epilepsy associated with cerebral palsy was used as dependent variable, and atrophy, hydrocephalus, lacunar state, periventricular leukomalacia as independent variablesas, statistical significance was found only in the case of atrophy (OR:4.73, CI:1.85-12.09, p-0.0012).

Correlation between types of epilepsies (symptomatic and epileptic encephalopathies), response to antiepileptic treatment in mono or poly-therapy and forms of cerebral palsy identified in these patients

Twenty-eight (30.8\%) patients had resistant epilepsy. It must be underlined that $46.4 \%$ of these forms were associated with quadriplegia, mixed forms $14.2 \%, 10.71 \%$ with dyskinetic form and another $25 \%$ cases were associated with intermediate forms of cerebral palsy. The same frequency can be seen in the distribution of epileptic enceph-

Table IV. Imaging changes identified in the group of children with and without epilepsy.

\begin{tabular}{lccc}
\hline Variables & $\begin{array}{c}\text { Patients with CP } \\
\text { and epilepsy } \\
(88) \\
\mathrm{n}(\%)\end{array}$ & $\begin{array}{c}\text { Patients with } \\
\text { CP without } \\
\text { epilepsy } \\
(50) \\
\mathrm{n}(\%)\end{array}$ & p value* \\
\hline $\begin{array}{l}\text { Normal imaging } \\
\text { Abnormal imaging }\end{array}$ & $\begin{array}{l}6(6.8) \\
\text { (all findings) }\end{array}$ & $11(22.0)$ & 0.01 \\
$\begin{array}{l}\text { Cerebral malformations } \\
\text { Gray matter insult }\end{array}$ & $24(27.3)$ & $17(34.0)$ & 0.52 \\
Non-specific atrophy & $6(6.8)$ & $5(10.0)$ & 0.73 \\
periventricular leukomalacia, & $33(37.5)$ & $7(16.0)$ & 0.01 \\
including IVH & $17(19.3)$ & $5(10.0)$ & 0.23 \\
Hydrocephalus & $22(25,0)$ & $9(18.0)$ & 0.56 \\
Cystic cavitation & $19(21.6)$ & $9(18.0)$ & 0.77 \\
\hline Abbreviations: CP-cerebral palsy, IVH- intraventricular haemorrhage, ${ }^{*}$ chi test square
\end{tabular}

alopathies, $53.3 \%$ of which were associated with quadriplegia (Table V).

Of the 91 epileptic patients, $49(53.8 \%)$ had onset of seizures before the age of one year, of whom $21(42.8 \%)$ presented treatment-resistant forms. The onset of seizures after the age of one year was identified in $42(46.1 \%)$ patients, only $8(19 \%)$ of them presenting treatment-resistant forms of epilepsy. Therefore, early onset of epilepsy can be an indicator of the epileptic forms severity (OR:3.09, 95\% CI:1.187-8.061, p-0.01).

\section{Discussions}

A study conducted on 374 children with cerebral palsy in Norway showed only a $28 \%$ prevalence of epilepsy among these patients, which may be explained due to the high standard of living which brings significant reduction to the risk factors of cerebral palsy [18]. In our study, $51.4 \%$ of patients with cerebral palsy have developed epilepsy, the result is consistent with data reported by others $[8,10,17]$. The percentages vary depending on the type of cerebral palsy. In the specialized literature, forms with quadriplegia and spastic hemiplegia are associated with epilepsy in the highest percentage $[7,19]$. Thus, Zelnic $\mathrm{N}$ et al [8] identify $49.2 \%$ respectively $27.7 \%$ of these forms in epileptic patients. In our study quadriplegia associated with epilepsy was identified in $35.2 \%$ of the cases, patients presenting this clinical picture being much more exposed. In contradiction, the study by Sellier E et al [20] on a group of 9654 patients registered in 17 European regions, shows an increased frequency of epilepsy in the dyskinetic group (51.6\%). Pure CP dyskinetic forms are those that usually has basal ganglia lesions that do not generate seizures; such associations were encountered in our study as well. In the quadriplegic group, the most common types of seizures were the partial seizures with or without secondary generalization $(34.4 \%)$, followed by GTCS $(12.5 \%)$ and infantile spasms (9.4\%); similar percentages are found in the literature too [15].

The age of onset of epilepsy was frequently analyzed in various studies that have concluded that this is often under the age of one year, and that the earlier the onset of seizures is, the more severe forms of epilepsy will develop [8,20,21]. In our study we identified a high percentage of drug resistant forms of epilepsy (30.8\%), nearly half of them (46.4\%) being associated with quadriplegia. In addition, the onset of epilepsy under the age of one year (53.8\%) may be a prognostic factor of severity in their evolution; these results are consistent with those existing in the scientific literature.

The presence of neonatal seizures is an important risk factor for the subsequent development of epilepsy, especially for those with quadriplegia. The incidence of epilepsy in infants with neonatal seizures has been described in the literature as having values between $10-50 \%[22,23]$. In a study by Garfinkel J and Shevell MI [12], 30.1\% of a total of 120 on-term newborns with neonatal seizures have developed cerebral palsy, $58 \%$ of them being subse- 
Table V. Correlation between forms of CP, types of epilepsy, seizure control and response to antiepileptic treatment

\begin{tabular}{|c|c|c|c|c|}
\hline CP subgroup & Epilepsy subtypes & Seizures control & Non responsive type & AED number \\
\hline $\begin{array}{l}\text { Quadriplegia } \\
N=32\end{array}$ & $\begin{array}{l}\text { SE }-16 \\
\text { EE- } 16\end{array}$ & $\begin{array}{c}<6 \text { mo: } 2 \\
6 \text { mo-1 y: } 3 \\
1-2 \text { y: } 6 \\
>2 \text { y: } 8\end{array}$ & $\begin{array}{c}13 \\
\text { From this: } \\
4 \text { symptomatic West } \\
4 \text { Lennox Gastaut sy }\end{array}$ & $\begin{array}{l}\text { Monotherapy } 3 \\
2 \text { AED }-11 \\
2-5 \text { AED-17 }\end{array}$ \\
\hline $\begin{array}{l}\text { Diplegia } \\
\mathrm{N}=5\end{array}$ & $\begin{array}{c}\text { SE- } 5 \\
\text { EE - } 0 \\
\text { Sz-free - } 1\end{array}$ & $\begin{array}{c}<6 \text { mo: } 1 \\
6 \text { mo-1 y: } 0 \\
1-2 \text { y: } 2 \\
>2 \text { y: } 2\end{array}$ & 0 & $\begin{array}{c}\text { Monotherapy- } 3 \\
2 \text { AED - } 2 \\
2-5 \text { AED- } 0\end{array}$ \\
\hline $\begin{array}{l}\text { Hemiplegia } \\
N=21\end{array}$ & $\begin{array}{c}\mathrm{SE}-21 \\
\mathrm{EE}-0 \\
\text { sz-free - } 2\end{array}$ & $\begin{array}{c}<6 \text { mo: } 1 \\
6 \text { mo-1 y: } 1 \\
1-2 \text { y: } 8 \\
>2 \text { y: } 11\end{array}$ & 1 & $\begin{array}{c}\text { Monotherapy- } 12 \\
2 \text { AED- } 6 \\
2-5 \text { AED- } 2 \\
\text { withdrawal of medication - } 1\end{array}$ \\
\hline $\begin{array}{l}\text { Ataxic } \\
\mathrm{N}=8\end{array}$ & $\begin{array}{c}\text { SE - } 15 \\
\text { EE - } 0 \\
\text { Sz-free - } 1\end{array}$ & $\begin{array}{c}<6 \text { mo: } 0 \\
6 \text { mo-1 y: } 0 \\
1-2 \text { y: } 2 \\
>2 \text { y: } 8\end{array}$ & - & $\begin{array}{c}\text { Monotherapy- } 3 \\
2 \text { AED- } 7 \\
2-5 \text { AED- } 6 \\
\text { withdrawal of medication - } 3\end{array}$ \\
\hline $\begin{array}{l}\text { Dyskinetic } \\
\mathrm{N}=5\end{array}$ & $\begin{array}{l}\text { SE-3 } \\
\text { EE -2 }\end{array}$ & $\begin{array}{c}<6 \text { mo: } 3 \\
6 \text { mo-1 y: } 0 \\
1-2 \text { y: } 0 \\
>2 \text { y: } 2\end{array}$ & 3 & $\begin{array}{c}\text { Monotherapy - } 2 \\
2 \text { AED-0 } \\
\text { 2-5 AED-3 }\end{array}$ \\
\hline $\begin{array}{l}\text { Mixed } \\
\mathrm{N}=9\end{array}$ & $\begin{array}{l}\text { SE -5 } \\
\text { EE - } 4\end{array}$ & $\begin{array}{c}<6 \text { mo: } 0 \\
6 \text { mo-1 y: } 2 \\
1-2 \text { y: } 2 \\
>2 \text { y: } 1\end{array}$ & $\begin{array}{c}4 \\
\text { From this: } \\
1 \text { West sy } \\
1 \text { Lennox Gastaut sy }\end{array}$ & $\begin{array}{c}\text { Monotherapy - } 1 \\
2 \text { AED - } 3 \\
2-5 \text { AED - } 6\end{array}$ \\
\hline $\begin{array}{l}\text { Not classified } \\
\mathrm{N}=11\end{array}$ & $\begin{array}{l}\text { SE -5 } \\
\text { EE- } 7\end{array}$ & $\begin{array}{l}<6 \text { mo: } 0 \\
6 \text { mo-1 y: } 1 \\
1-2 \text { y: } 1 \\
>2 \text { y: } 2\end{array}$ & 7 & $\begin{array}{c}\text { Monotherapy - } 2 \\
2 \text { AED - } 2 \\
2-5 \text { AED - } 7\end{array}$ \\
\hline
\end{tabular}

quently diagnosed with spastic quadriplegia and epilepsy. In our study, those patients with quadriplegia and a history of neonatal seizures presented a 12.8 times greater risk to develop epilepsy; this association represents a strong predictive factor. Neonatal seizures in on-term infants were more frequently associated with the onset of epilepsy compared with premature infants, in contradiction to results obtained by Zelnic et al [8] where no difference between the two groups was seen. These results are also in contradiction with those found in the prospective study of Ronen et al [13], indicating the presence of more frequent neonatal seizures in preterm infants than in on-term infants who developed epilepsy.

In the specialized literature, different studies show different results concerning the association between gestational age, birth weight and the onset of epilepsy in children with CP. In Kulak's study [5], low birth weight associated with low gestational age was not identified as a risk factor in epilepsy. Zelnik [8], Selier [20] found epilepsy more frequently associated with on-term infants weighing more than $2500 \mathrm{~g}$ compared with premature infants under 32 weeks with very low weight. In our study, aspects of resuscitation, mechanical ventilation, and prolonged jaundice were not identified as increasing the risk to develop epilepsy, being distributed in similar proportions in both groups. Hypoxic pre- and perinatal suffering quantified by low Apgar score has been found more frequently in the group of patients who later developed epilepsy. Another risk factor was the TORCH syndrome, from this, cytomegalovirus was significantly increased. A number of factors such as neonatal seizures, multiple and pathological pregnancies, and low Apgar score at 1 minute were not independently associated with epileptic forms by multivariable logistic re- gression, but constituted important risk factors in the development of epilepsy in children with cerebral palsy.

Abnormal imaging was identified in the group of patients with cerebral palsy and epilepsy. Cerebral atrophy was most often associated with epileptics, a finding consistent with data found in the literature $[3,5,7,8]$.

\section{Limitations of the study}

Classifying forms of cerebral palsy by severity would be predictive of the onset and evolution of epilepsy. The absence of brain imaging in many cases, and particularly the small number of MRI investigation limited the identification of a correlation between the clinical picture of $\mathrm{CP}$ and seizures. Also, periodic examinations of non-epileptic patients EEGs could identify more cases with an early risk for developing epilepsy, and in these situations the introduction of antiepileptic drugs as protector of epileptogenesis should be considered. In addition, the lack of video EEG monitoring in epileptic patients makes it impossible to accurately classify the type of seizures especially in patients with dyskinetic forms. All these require continued studies in order to clarify and support the suggested predictive risk and prognostic factors of epilepsy in this category of patients.

\section{Conclusions}

A history of neonatal seizures, particularly in patients with quadriplegia, is an important risk factor for the subsequent development of epilepsy in these children. Compared with premature infants, on-term infants with neonatal seizures are more often at risk to develop epilepsy. Full-term newborns are more exposed than pre-term newborns, while pre- and perinatal hypoxic distress quantified by low Apgar 
score, the presence of opportunistic infections such as cytomegalovirus, multiple and pathologic pregnancies being the most frequently found factors associated. The frequent association of cerebral changes in patients with epilepsy, especialy of cerebral atrophy and the onset of epilepsy under the age of one year, points to it as a factor aggravating prognosis. Most of drug resistant epilepsy are associate with quadriplegia.

\section{Acknowledgements}

This papers was published under the frame of European Social Found, Human Resources Development Operational Programme 2007-2013, project no. POSDRU/159/1.5/S/136893.

\section{References}

1. Benga I, Vințan M. Paralizille cerebrale, in: Benga I, Cristea A, Vințan M: Ghid de diagnostic și tratament de Neurologie Pediatrică, ed med Univ „Iuliu Hațieganu”, Cluj Napoca, 2006;112-148.

2. Cans C. A collaboration of cerebral palsy surveys and registers. Dev. Med Child Neurol. 2000;42:816-824.

3. Minciu I. Corelații clinico-imagistice în paralizia cerebrală. Revista Română de Pediatrie. 2012;59(2):175-184.

4. Krageloh Mann I, Bax M. Cerebral Palsy, in: Aicardi J (ed). Diseases in nervous system in Childhood. 3rd edit. Mac Keith Press, London. 2009; 7:210-242.

5. Kulak W, Sobaniec W. Risk factors and prognosis of epilepsy in children with cerebral palsy in north- eastern Poland. Brain Dev. 2003;27:499506.

6. Kwong K, Wong SN, So KT. Epilepsy in children with cerebral palsy. Pediatr Neurol. 1998;19:313-316.

7. Gururaj AK, Sztriha L, Bener A, Dawadou A, Eapen V. Epilepsy in children with cerebral palsy. Seizure. 2003;12:110-114.

8. Zelnik N, Konopnicki M, Bennett-Back O, Castel-Deutsch T, Tirosh E. Risk factors for epilepsy in children with cerebral palsy. Eur J Paediatr
Neurol. 2010;14:67-72.

9. Singer HS. Cerebral Palsy, in: Singer HS, Mink JW, Gilbert DL, Jankovic $J$ (eds): Movement Disorders in Chilhood, Saunders Elsevier Inc., Philadelphia, 2010;219-228.

10. Singhi $P$, Jagirdar S, Khandelwal N, Malhi P. Epilepsy in children with cerebral palsy. J Child Neurol. 2003;18:174-179.

11. Hundozi-Hysenaj $\mathrm{H}$, Boshnjaku-Dallku I. Epilepsy in children with cerebral palsy, Pediatr Neurol. 2008;6(1):43-46.

12. Garfinkle J, Shevell Ml. Cerebral palsy, developmental delay, and epilepsy after neonatal seizures. Pediatr Neurol. 2011;44:88-96.

13. Ronen GM, Buckley D, Penney S, Streiner DL, Long-term prognosis in children with neonatal seizures: a population based study. Neurology. 2007;69:1816-22.

14. Commission on Classification and Terminology of the International League against Epilepsy. Proposal for revised classification of epilepsies and epileptic syndromes. Epilepsia. 1989;30:389-99.

15. Gul Mert G, Incecik F, Altunbasak S, Herguner O, Kurthan Mert M, Kiris N, Unal I. Factors affecting epilepsy development and epilepsy prognosis in cerebral palsy. Pediatr Neurol. 2011;45(2):89-94.

16. Lizana JR, Rodriguez-Lucenilla MI, Aguilera-Lopez P, Aguirre-Rodriguez J, Cassinello-Garcia E. A study of drug-resistant childhood epilepsy testing the new ILAE criteria. Seizure. 2012;21:266-272.

17. Kent RM. Cerebral palsy, in: Barnes MP, Good DC (eds) : Handbook of Clinical Neurology, Neurological Rehabilitation. e-Book, 2013;110:443459.

18. Andersen GL, Irgens LM, Haagaas I, Skranes JS, Meberg AE, Vik T. Cerebral palsy in Norway: prevalence, subtypes and severity. Eur J Paediatr Neurol. 2008;12(1):4-13.

19. Singhi P, Arushi Gahlot Saini. Changes in the clinical spectrum of cerebral palsy over two decades in North India- An Analysis of 1212 Cases, Journal Tropical Pediatrics. 2013;59 (6):434-440.

20. Sellier E, Uldall P, Caldo E, Sigurdardottir S, Torrioly MG et al. Epilepsy and cerebral palsy: characteristics and trends in children born in 19761998. Eur J Paediatr Neurol. 2012;16:48-55.

21. Knezević-Pogancev M. Cerebral palsy and epilepsy, Med Pregl. 2010;63(7-8):527-530.

22. Clancy RR, Legido A. Postnatal epilepsy after EEG-confirmed neonatal seizures. Epilepsia. 1991;32:69-76.

23. Toet M, Groenendaal F, Osredkar D, vanHuffelen A, deVries L. Postneonatal epilepsy following amplitude-integrated EEG-detected neonatal seizures. Pediatr Neurol. 2005;32:241-247. 